\title{
Effect of Dissolved Oxygen on Growth Yield and Aldolase Activity in Chemostat Culture of Azotobacter vinelandii
}

\author{
By S. NAGAI, Y. NISHIZAWA, M. ONODERA And S. AIBA \\ Institute of Applied Microbiology, University of Tokyo, Tokyo, Japan
}

(Accepted for publication 25 March I97I)

\begin{abstract}
SUMMARY
Glucose-limited and oxygen-limited chemostat cultures of Azotobacter vinelandii were agitated at $240,340,560$ and $780 \mathrm{rev} / \mathrm{min}$. In the oxygen-limited culture the growth yield ranged from 0.2 to $0.25 \mathrm{mg}$. bacteria $/ \mathrm{mg}$. glucose, considerably higher than 0.03 to 0.18 observed when glucose was limiting. This finding suggests that the dissolved oxygen interferes in the metabolism of growing Azotobacter. Aldolase activity, but not that of glyceraldehyde-3-phosphate dehydrogenase, isocitrate dehydrogenase or isocitrate lyase, was proportional to dissolved oxygen concentration in each culture. The carbon balance indicated no products other than the bacteria and carbon dioxide.
\end{abstract}

\section{INTRODUCTION}

It is well known that the oxygen uptake rate of Azotobacter vinelandii and its nitrogen-fixation capability are affected remarkably by oxygen tension (Parker \& Scutt, 1960; Dilworth, 1962). Tschapek \& Giambiagi (I955) reported that the multiplication rate and nitrogenfixing efficiency of Azotobacter increased on lowering the partial pressure of oxygen in the culture. The highest growth yield of Azotobacter was observed when the aeration rate was decreased to $18.7 \mathrm{mmoles} \mathrm{O}_{2} / \mathrm{l}$./h. (Khmel, Gabinskaya \& Ierusalimsky, I965).

The growth yield from glucose of Azotobacter vinelandii in a glucose-limited chemostat culture increased from 0.03 to $0 . \mathrm{I2}$, with an increase in dilution rate from 0.1 to $0.35 \mathrm{~h}^{-1}$ (Nagai, Nishizawa \& Aiba, I969). This finding suggested that the decrease of dissolved oxygen concentration in the chemostat culture accompanying the increase in dilution rate might have caused the increase in growth yield.

The principal purpose of the present work was to determine the most probable mode of oxygen interference with the growth yield by investigating oxygen-limited and glucoselimited chemostat cultures. According to the previous observation (Nagai, Nishizawa \& Aiba, 1969), most of the glucose consumed ( 83 to $97 \%$ ) was converted to carbon dioxide in the glucose-limited chemostat culture. This is an extremely high ratio of carbon dioxide evolved to glucose consumed.

A specific oxidative mechanism for glucose breakdown via the pentose cycle without the participation of phosphate hexokinase has been proposed by Mortenson \& Wilson (I954) and Mortenson, Hamilton \& Wilson (1955). The tricarboxylic acid cycle has also been observed by Stone \& Wilson (1952 $a, b, c)$. Consequently, it seemed worthwhile to measure the activities of aldolase, glyceraldehyde-3-phosphate dehydrogenase, isocitrate dehydrogenase and isocitrate lyase, all of which are relevant to carbon dioxide evolution. 


\section{METHODS}

Bacterium and culture conditions. Azotobacter vinelandii IAM 1078 (ATCC 9046) was grown at $30^{\circ} \pm 0.05^{\circ}$ in (g. l. ): glucose, $8 ; \mathrm{KH}_{2} \mathrm{PO}_{4}, 0.2 ; \mathrm{K}_{2} \mathrm{HPO}_{4}, 0.8 ; \mathrm{MgSO}_{4} \cdot 7 \mathrm{H}_{2} \mathrm{O}, 0.2 ; \mathrm{NaCl}$, 0.2 ; sodium citrate, $0.05 ; \mathrm{FeSO}_{4} \cdot 7 \mathrm{H}_{2} \mathrm{O}, 0.005 ; \mathrm{Fe}_{2}\left(\mathrm{SO}_{4}\right)_{3} .3 \mathrm{H}_{2} \mathrm{O}, 0.005 ; \mathrm{Na}_{2} \mathrm{MoO}_{4} .2 \mathrm{H}_{2} \mathrm{O}$, $0.00 \mathrm{I} ; \mathrm{CaCl}_{2} \cdot 2 \mathrm{H}_{2} \mathrm{O}, 0.0 \mathrm{I} ; \mathrm{pH}$ was 7.0 to $7 \cdot 2$. Four series of continuous cultures at constant agitation speeds, $240,340,560$ and $780 \mathrm{rev} . / \mathrm{min}$. were carried out. Culture equipment used was described previously (Nagai et al. 1969).

Analytical procedures. Bacterial mass, residual glucose and carbon dioxide evolution rate in each chemostat culture were determined as described previously; conditions for the establishment of chemostat cultures were also as before (Nagai et al. I969). Dissolved oxygen concentration was determined using a Beckman-Toshiba type 777 oxygen electrode.

Preparation of cell-free extract. Samples taken from the chemostat overflow (about $1000 \mathrm{ml}$.) were centrifuged at $8000 \mathrm{~g}$ for $5 \mathrm{~min}$. at $5^{\circ}$, washed with cold saline $(0.8 \%)$ and again centrifuged at $8000 \mathrm{~g}$ for $5 \mathrm{~min}$. The sediment was washed with phosphate buffer $(0.015 \mathrm{M}, \mathrm{pH} 7.0)$ and homogenized (B. Braun Melsungen 2876) using glass beads of diameter $0.1 \mathrm{~mm}$. The homogenized suspension was centrifuged at $25,000 \mathrm{~g}$ for $10 \mathrm{~min}$. at $5^{\circ}$. The supernatant solution was used for the determination of enzyme activities.

Aldolase. A kit (C. F. Boehringer Mannheim GmbH, Biochemica, Germany) was used. The rate of decrease in $\mathrm{NADH}_{2}$ was measured at $340 \mathrm{~nm}$. and the molecular extinction was taken as $6.22 \times 10^{6} \mathrm{~cm} .{ }^{2}$ mole.

Glyceraldehyde-3-phosphate dehydrogenase. Krebs's (1955) method was modified in that NADP was used instead of NAD. The rate of increase in $\mathrm{NADPH}_{2}$ was measured at $340 \mathrm{~nm}$. and the molecular extinction was also taken as $6 \cdot 22 \times 10^{6} \mathrm{~cm} .{ }^{2} / \mathrm{mole}$.

Isocitrate lyase. Dixson \& Kornberg's (1959) method was used. Glyoxylic phenylhydrazone oxidized was measured at $324 \mathrm{~nm}$. and the molecular extinction was taken as $\mathrm{I} \cdot 7 \times$ $10^{7} \mathrm{~cm} .^{2} /$ mole.

Isocitrate dehydrogenase. Kornberg's (1955) method was employed. The rate of increase in $\mathrm{NADPH}_{2}$ was measured at $340 \mathrm{~nm}$., taking the molecular extinction as $6.22 \times 10^{6} \mathrm{~cm} .{ }^{2} /$ mole.

Soluble protein. The method of Gornall, Bardawill \& David (1949) was used.

\section{RESULTS AND DISCUSSION}

Four series of chemostat cultures of Azotobacter vinelandii were carried out at constant agitation speeds of $240,340,560$ and $780 \mathrm{rev} / \mathrm{min}$. Data for those at 340 and $560 \mathrm{rev}$. $/ \mathrm{min}$. are shown in Fig. I and 2. When agitation was maintained at $340 \mathrm{rev} . / \mathrm{min}$. typical oxygenlimited chemostat cultures were obtained as shown in Fig. I. In this run, dissolved oxygen concentrations were controlled at low levels ranging from 0.1 to 0.4 p.p.m., but glucose concentrations were fairly high; the lowest level observed was $0.44 \mathrm{mg} . / \mathrm{ml}$. (440 p.p.m.) at a dilution rate of $\mathrm{O}^{\prime} \mathrm{I} \mathrm{h} \mathrm{h}^{-1}$ (see Fig. I). In the glucose-limited chemostat culture of Nagai et al. (1969) glucose concentration was around $\mathrm{Io}^{-3} \mathrm{mg} . / \mathrm{ml}$. (I p.p.m.). Experimental data for $240 \mathrm{rev}$. $/ \mathrm{min}$. were similar to Fig. I (oxygen-limited), but the cell concentration was lower because of the lower supply rate of oxygen.

Fig. 2 shows the experimental results when the agitation speed was moderate at $560 \mathrm{rev}$. min. In contrast to Fig. I, glucose and dissolved oxygen concentrations exhibited peculiar patterns with respect to the dilution rate. Glucose concentration was nearly zero when the dilution rate was less than 0.2 h. $^{-1}$ (Fig. 2), but the concentration became higher when the 
dilution rate was greater than $0.2 \mathrm{~h}^{-1}$. Apparently, the chemostat culture obtained at an agitation speed of $560 \mathrm{rev}$. $/ \mathrm{min}$. was characterized by two limiting factors. It was oxygenlimited at dilution rates greater than $0.2 \mathrm{~h}^{-1}$, and glucose-limited when the dilution rate was lower than $0 \cdot 2 \mathrm{~h}^{-1}$.

Growth yield from glucose. The growth yield from glucose of Azotobacter vinelandii in glucose-limited chemostat culture increased from 0.03 to $0.12 \mathrm{mg}$. bacteria/mg. glucose, following an increase in dilution rate from $0 . \mathrm{I}$ to $0.35 \mathrm{~h}^{-1}$ when the glucose concentration

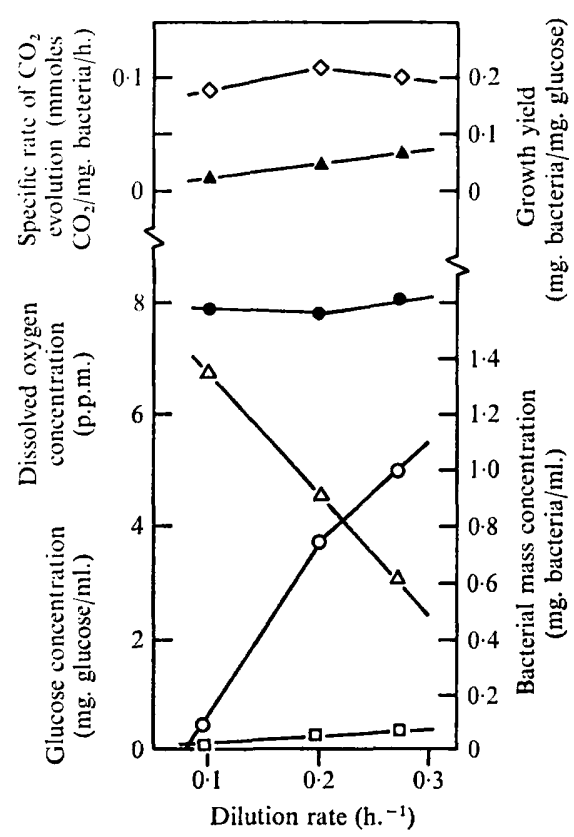

Fig. I

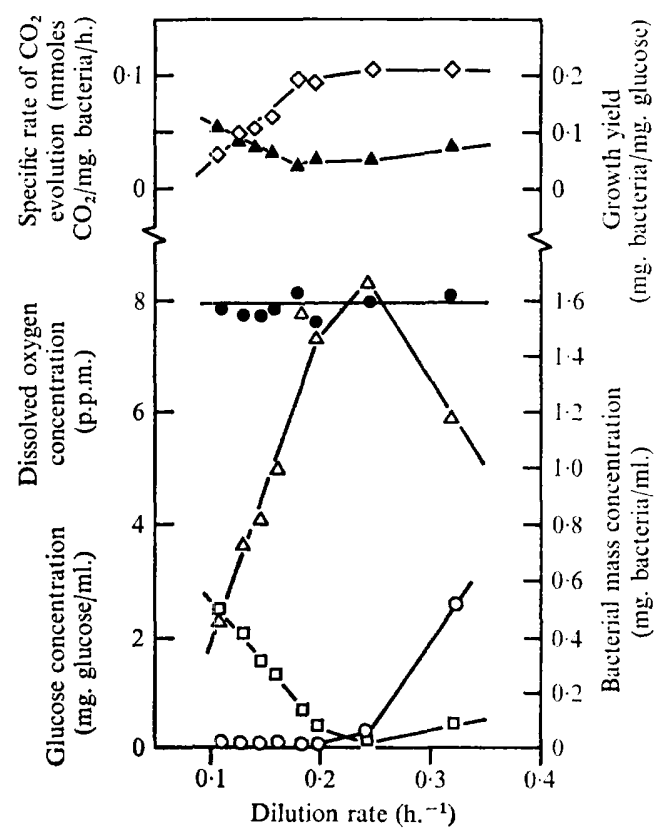

Fig. 2

Fig. I. Bacterial mass, glucose, and dissolved oxygen concentrations, specific rate of $\mathrm{CO}_{2}$ evolution and yield from glucose in oxygen-limited chemostat culture of Azotobacter vinelandii. Agitation speed, $340 \mathrm{rev} . / \mathrm{min}$. $\bigcirc-\mathrm{O}$, Glucose concentration in chemostat culture; $\longrightarrow$, glucose concentration in fresh medium; $\triangle-\Delta$, bacterial concentration; $\square-\square$, dissolved oxygen concentration; $\Delta-\Delta, \mathrm{CO}_{2}$ evolution; $\diamond-\diamond$, growth yield from glucose.

Fig. 2. Bacterial mass, glucose and dissolved oxygen concentrations, specific rate of $\mathrm{CO}_{2}$ evolution and yield from glucose in glucose-limited (dilution rate $<0.2 \mathrm{~h} .^{-1}$ ) and in oxygen-limited (dilution rate $>0.2 \mathrm{~h}^{-1}$ ) chemostat culture of Azotobacter vinelandii. Agitiation speed, $560 \mathrm{rev} . \mathrm{min}$. $\mathrm{O}-\mathrm{O}$, Glucose concentration in chemostat culture; - - glucose concentration in fresh medium; $\triangle-\triangle$, bacterial concentration; $\square-\square$, dissolved oxygen concentration; $\Delta-\Delta, \mathbf{C O}_{2}$ evolution; $\diamond-\diamond$, growth yield from glucose.

in the fresh medium was $5 \mathrm{mg}$./ml. (Nagai et al. 1969). In the oxygen-limited chemostat culture in the present work (Fig. I) the yield was considerably higher, ranging from 0.2 to 0.23 . In the glucose-limited culture (glucose concentration in fresh medium $8 \mathrm{mg} . / \mathrm{ml}$.) the yield agreed with the previous finding (Nagai et al. 1969).

These results suggested that the growth yield depended on the dissolved oxygen concentration. The relationship between the growth yield and dissolved oxygen concentration is summarized in Fig. 3, extracting relevant data from the experiments at 240, 340, 560 and $780 \mathrm{rev} . \mathrm{min}$.

A similar observation was presented by Dalton \& Postgate (1969) for chemostat cultures 
of Azotobacter chroococcum. They suggested that the physiological meaning of the term 'carbon-limited' becomes equivocal, because nitrogen-fixation efficiency which ought to have been limited by carbohydrate was decreased by oxygen.

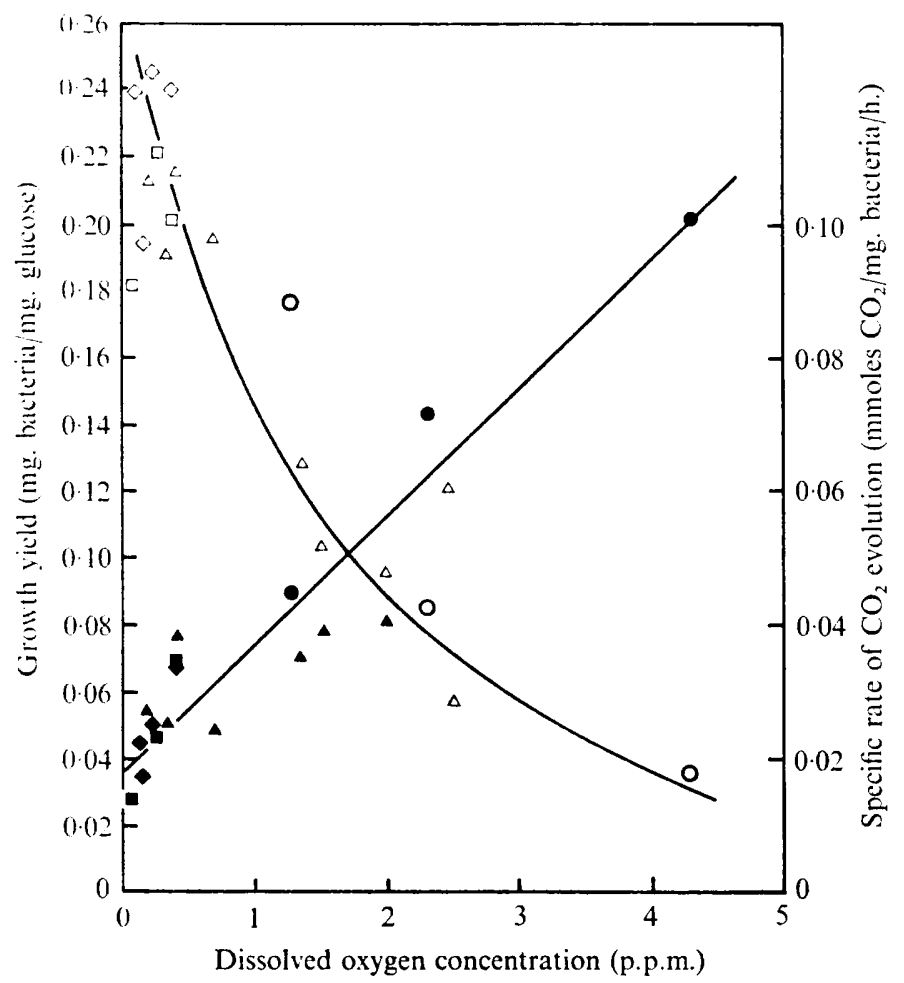

Fig. 3. Effects of dissolved oxygen concentration on yield from glucose and specific evolution rate of carbon dioxide in chemostat culture of Azotobacter vinelandii. Data points were reproduced from Fig. I and 2 and additional data from experiments at $240 \mathrm{rev} . / \mathrm{min}$. (oxygen-limited) and $780 \mathrm{rev} . / \mathrm{min}$. (glucose-limited) were cited. Open and solid symbols indicate growth yield from glucose and specific evolution rate of carbon dioxide, respectively. $0,0,780 \mathrm{rev} . / \mathrm{min} . ; \Delta, \boldsymbol{\Lambda}$, $560 \mathrm{rev} . \mathrm{min} . ; \square, \mathbf{\square}, 340 \mathrm{rev} . / \mathrm{min}$; $\diamond, \diamond, 240 \mathrm{rev} . / \mathrm{min}$.

Carbon balance for glucose. Fig. 3 shows that the specific rate of carbon dioxide evolution increased almost in proportion to the increase in dissolved oxygen concentration. If bacterial mass and carbon dioxide are the principal products formed from glucose, one can write:

Then

Glucose carbon consumed $=$ Bacterial carbon produced $+\mathrm{CO}_{2}$ evolved.

where

$$
\alpha_{3} v=\alpha_{1} \mu_{s}+\alpha_{2} Q_{\mathrm{co}_{2}}
$$

$v=-\frac{\mathrm{I}}{X} \frac{\mathrm{d} S}{\mathrm{~d} t}=$ Specific rate of glucose consumption, mg. glucose $/ \mathrm{mg}$. bacteria $/ \mathrm{h}$;

$\mu_{x}=\frac{\mathrm{I}}{X} \frac{\mathrm{d} X}{\mathrm{~d} t}=D$, dilution rate, $\mathrm{h}^{-1}$

$Q_{\omega_{2}}=\frac{\mathrm{I}}{X} \frac{\mathrm{dCO}_{2}}{\mathrm{~d} t}=$ Specific rate of carbon dioxide evolution, mmoles $\mathrm{CO}_{2} / \mathrm{mg}$. bacteria $/ \mathrm{h}$.;

$\alpha_{1}=$ Carbon content of Azotobacter vinelandii

$=0.45 \mathrm{mg}$. carbon $\mathrm{mg}$.; 
$\alpha_{2}=$ Stoichiometric constant for carbon in $\mathrm{CO}_{2}$

$=\mathrm{I} 2 \mathrm{mg}$. carbon $/ \mathrm{mmole} \mathrm{CO}_{2}$;

$\alpha_{3}=$ Stoichiometric constant for carbon in glucose

$=0.40(=72 / 180) \mathrm{mg}$. carbon $/ \mathrm{mg}$. glucose.

Rearranging equation (2),

where

$$
\begin{aligned}
\frac{\mathrm{I}}{Y_{X / s}} & =\frac{\alpha_{1}}{\alpha_{3}}+\frac{\alpha_{2}}{\alpha_{3}} \frac{Q_{\mathrm{Co}_{2}}}{\mu_{X}} \\
& =\mathrm{I} \cdot \mathrm{I} 2+30 \frac{Q_{\mathrm{Co}_{2}}}{\mu_{X}}
\end{aligned}
$$

$$
Y_{X / s}=\text { Growth yield }=\frac{\mu_{x}}{v}(\mathrm{mg} . \text { bacteria } / \mathrm{mg} \text {. glucose }) \text {. }
$$

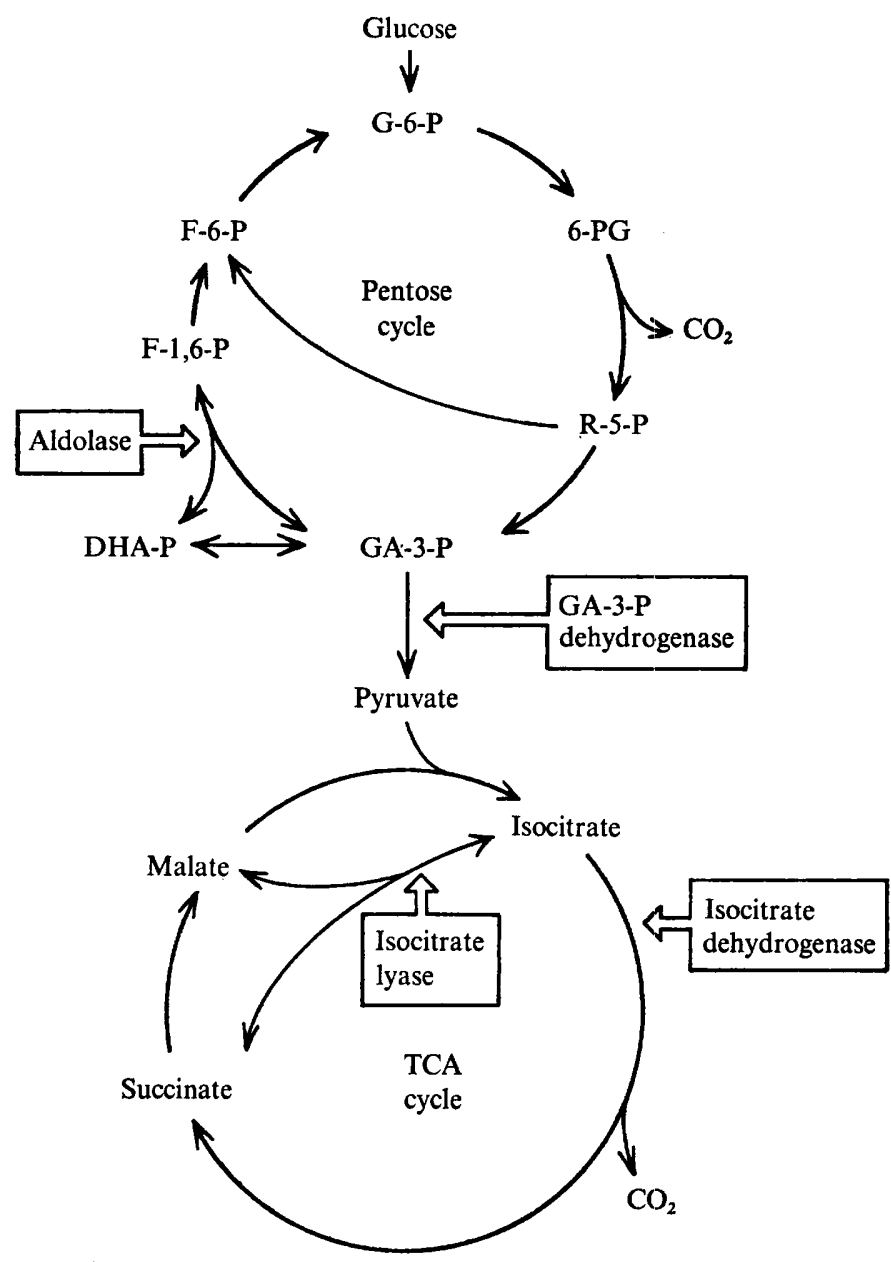

Fig. 4. Specific oxidative pathway of glucose degradation in Azotobacter vinelandii (Stone et al. I952 $a, b, c$; Mortenson et al. I954, I955). G-6-P = glucose-6-phosphate; 6-PG = 6-phosphogluconate; $\quad R-5-P=$ ribulose-5-phosphate; $\quad$ GA-3-P = glyceraldehyde-3-phosphate; $\quad F-6-P=$ fructose-6-phosphate; F-1, 6-P = fructose-I, 6-diphosphate; DHA-P = dihydroxyacetonaphosphate. 
When the data from the four experiments at $240,340,560$ and $780 \mathrm{rev} / \mathrm{min}$. (Fig. 3) were plotted as I $Y_{x \text { s }}$ against $Q_{\mathrm{co}_{2}} / \mu_{x}$, a good straight-line relationship of equation (3) was found. This supported the assumption that no appreciable amount of metabolites other than bacteria and carbon dioxide was produced in both oxygen-limited and glucose-limited chemostat cultures.

The specific oxidative mechanism for glucose breakdown is represented schematically in Fig. 4. The scheme shows that glyceraldehyde-3-phosphate is branched either to fructose-1,6diphosphate via aldolase or to pyruvate via glyceraldehyde-3-phosphate dehydrogenase. Isocitrate can be converted to succinate and malate via isocitrate dehydrogenase or to the

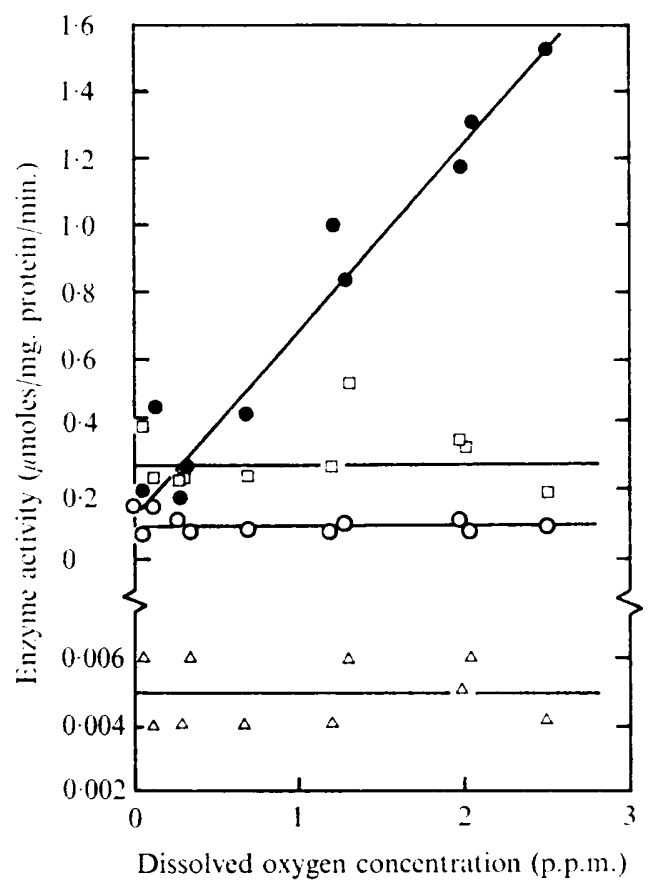

Fig. 5. Effect of dissolved oxygen concentration on activities of aldolase (O), glyceraldehyde-3phosphate dehydrogenase $(O)$, isocitrate lyase $(\triangle)$ and isocitrate dehydrogenase $(\square)$ in glucoselimited and oxygen-limited chemostat cultures of Azotobacter vinelandii.

same acids via isocitrate lyase. Enzyme activities related to these major biochemical steps are obviously concerned in the evolution of carbon dioxide; for example, if aldolase activity is high, recycling of glyceraldehyde-3-phosphate through the pentose cycle may become preponderant culminating in the more active evolution of carbon dioxide.

Activities of the four enzymes in the chemostat cultures at an agitation speed of $560 \mathrm{rev}$. min. are shown in Fig. 5.

The experimental fact that a fairly large range of dissolved oxygen concentration was observed on changing the dilution rate in this particular chemostat is the reason for using the data obtained at $560 \mathrm{rev}$. $/ \mathrm{min}$. (given in Fig. 2). It is evident that activities of isocitrate dehydrogenase, isocitrate lyase and glyceraldehyde-3-phosphate dehydrogenase remained fairly constant, while aldolase activity increased when the cells were subjected to an environment higher in dissolved oxygen. These results are consistent with the observation that the yield from glucose decreased appreciably with the increase in dissolved oxygen concentra- 
tion because an increase in aldolase activity would direct more glucose breakdown into the pentose cycle, evolving more carbon dioxide and thus decreasing metabolism via the tricarboxylic acid cycle leading to biosynthesis.

\section{REFERENCES}

Dalton, H. \& Postgate, J. R. (1969). Growth and physiology of Azotobacter chroococcum in continuous culture. Journal of General Microbiology 56, 307-319.

Dilworth, M. J. (1962). Oxygen inhibition in Azotobacter vinelandii. Biochimica et biophysica acta 56, $127-$ 138.

Dixson, G. H. \& KornberG, H. L. (1959). Assay method for key enzymes of the glyoxylate cycle. Biochemical Journal 72, $3 \mathbf{P}$.

Gornall, A. G., Bardawill, C. S. \& David, M. M. (1949). Determination of serum proteins by means of the biuret reaction. Journal of Biological Chemistry 177, 751-766.

Khmel, I. A., Gabinskaya, K. N. \& Ierusalimsky, N. D. (1965). Growth and nitrogen fixation of Azotobacter vinelandii under different aeration conditions. Mikrobiologiya 34, 689-694.

KORNBERG, A. (1955). Isocitric dehydrogenase of yeast (TPN). In Methods in Enzymology, vol. 1, pp. 705-707. Edited by S. P. Colowick \& N. O. Kaplan. New York: Academic Press.

KreBs, E. G. (1955). Glyceraldehyde-3-phosphate dehydrogenase from yeast. In Methods in Enzymology, vol. I, pp. 407-4II. Edited by S. P. Colowick \& N. O. Kaplan. New York: Academic Press.

Mortenson, L. E. \& WiLSON, P. W. (1954). Initial stage in the breakdown of carbohydrate by Azotobacter vinelandii. Archives of Biochemistry and Biophysics 53, 425-435.

Mortenson, L. E., Hamilton, P. B. \& Wilson, P. W. (1955). Dissimilation of 6-phosphogluconate by Azotobacter vinelandii. Biochimica et biophysica acta 16, 238-244.

Nagai, S., Nishizawa, Y. \& Aiba, S. (1969). Energetics of growth of Azotobacter vinelandii in a glucoselimited chemostat culture. Journal of General Microbiology 59, I63-169.

PARKer, C. A. \& SCUTT, P. B. (1960). The effect of oxygen on nitrogen fixation by Azotobacter. Biochimica et biophysica acta 38, 230-238.

Stone, R. W. \& WiLson, P. W. (1952a). Respiratory activity of cell-free extracts of Azotobacter. Journal of Bacteriology 63, 605-6I7.

STONE, R. W. \& WiLSON, P. W. (I952 b). The effect of oxaloacetate on the oxidation of succinate by Azotobacter extracts. Journal of Bacteriology 63, 619-622.

Stone, R. W. \& Wilson, P. W. (1952c). The incorporation of acetate in acids of the citric acid cycle by Azotobacter extracts. Journal of Biological Chemistry 196, 22 I-225.

TsCHAPEK, M. \& GiambiaGI, N. (1955). Nitrogen fixation of Azotobacter in soil-its inhibition by oxygen. Archiv fiir Mikrobiologie 21, 376-390. 